\title{
Incidental removal of distal common bile duct adenoma after plastic stent placement
}

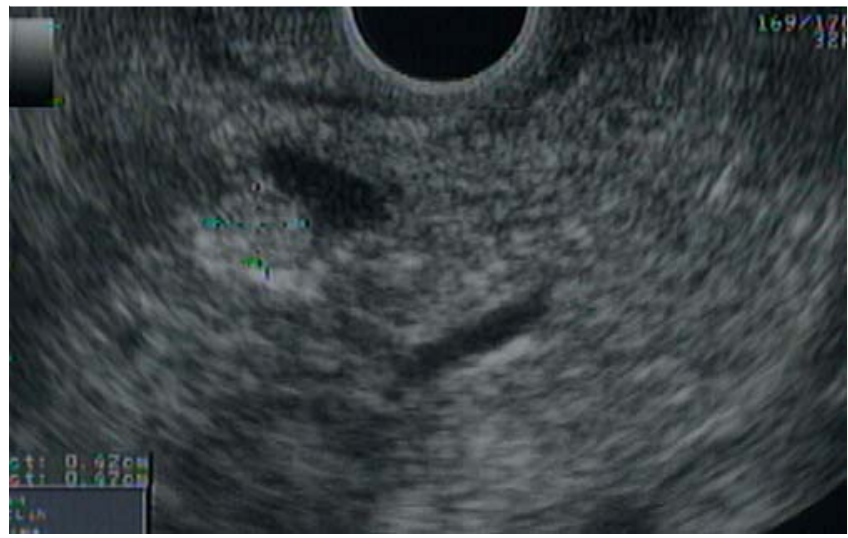

Fig. 1 Endoscopic ultrasound (EUS) showing an oval and non-shadowing mass at the distal common bile duct.

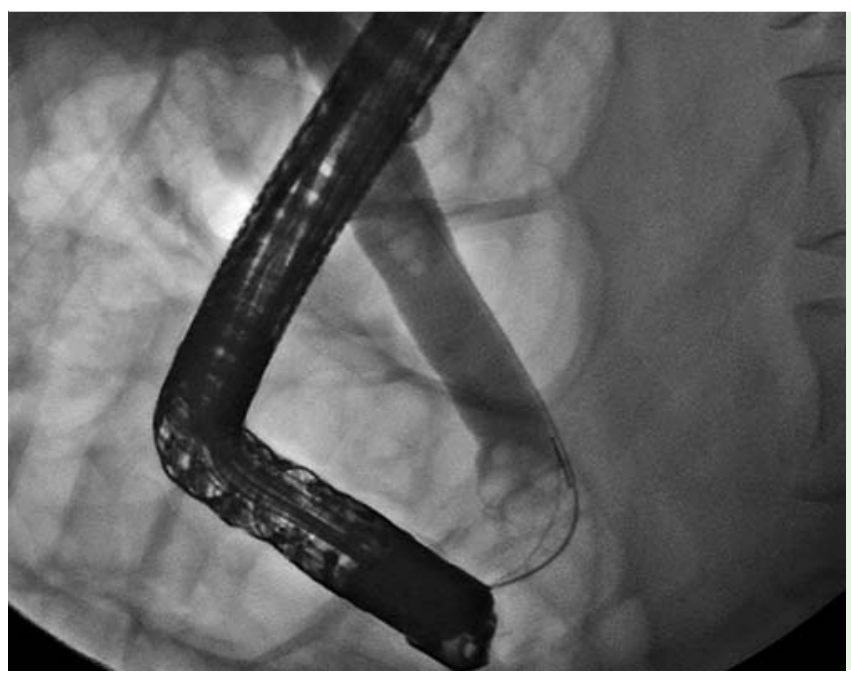

Fig. 3 Cholangiogram revealing an irregular filling defect at the distal common bile duct.

We report a case of a 53-year-old man who presented with a history of recurrent fever with intermittent jaundice over a few months. Ascending cholangitis was suspected. Abdominal ultrasound showed no gallstone and an only slightly dilated common bile duct (CBD). The patient's blood tests were normal.

The patient was referred for endoscopic ultrasound (EUS). In the endoscopic suite, the patient underwent deep sedation with full anesthetic monitoring. EUS was performed using a curvilinear echoendoscope (GF UC 140P; Olympus, Tokyo, Japan). The EUS findings showed an isoechoic oval shaped mass of $1.1 \times 0.7 \mathrm{~cm}$ at the distal CBD, without CBD dilation $(\checkmark$ Fig. 1). The patient then underwent endoscopic retrograde cholangiopancrea- tography (ERCP) using the duodenoscope (Olympus TJF-160, Olympus America, Center Valley, Pennsylvania, USA). The ampulla seemed normal on duodenoscopy ( $\bullet$ Fig. 2). A cholangiogram revealed a $12-\mathrm{mm}$ CBD with an irregular shaped filling defect, size $11 \times 20 \mathrm{~mm}$, at the distal CBD ( Fig.3). After endoscopic sphincterotomy, a polypoid mass of $1.5 \times 1.0 \mathrm{~cm}$ popped out ( Fig.4). The stalk of this polyp was inside the CBD.

We decided to take a biopsy from the polyp, and planned for polypectomy later, so a $10-\mathrm{Fr}$ plastic stent (Cotton-Leung biliary endoprosthesis, Wilson-Cook Medical Inc., Winston-Salem, North Carolina, USA) was inserted for biliary drainage ( Fig.5). Pathological analysis showed a tubular adenoma with low

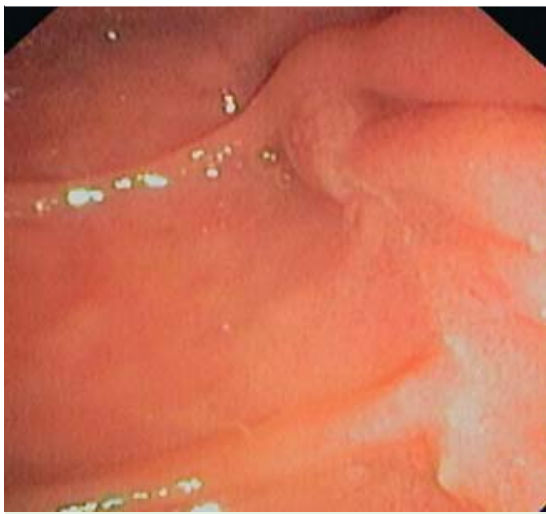

Fig. 2 Endoscopic view of the major ampulla.

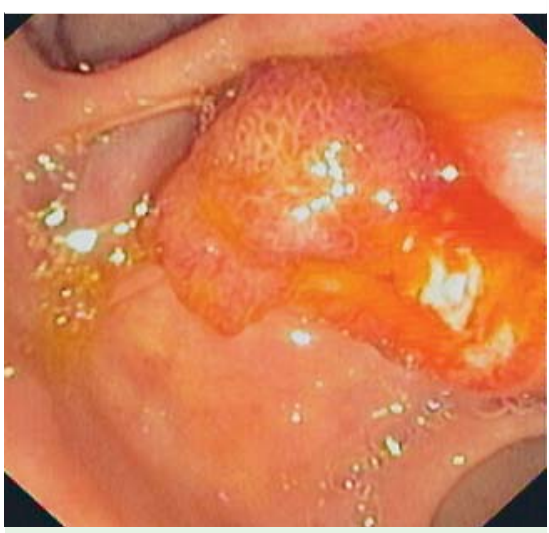

Fig.4 Endoscopic view showing prolapsed common bile duct adenoma.

grade dysplasia. The patient was scheduled for polypectomy 2 weeks later. During the second procedure, the polyp had disappeared, thus endoscopic retrograde cholangiography was performed. The cholangiogram showed no residual filling defect at the distal CBD. Overtube-assisted cholangioscopy using an ultraslim gastroscope showed only a residual small ulcer of about $4 \mathrm{~mm}$ diameter at the distal CBD ( $\bullet$ Fig.6). Our hypothesis for this unexpected event was that the pressure from the plastic stent resulted in stalk necrosis. To our knowledge [1 - 3], such a case has not been previously reported.

Endoscopy_UCTN_Code_TTT_1AR_2AK

Competing interests: None 


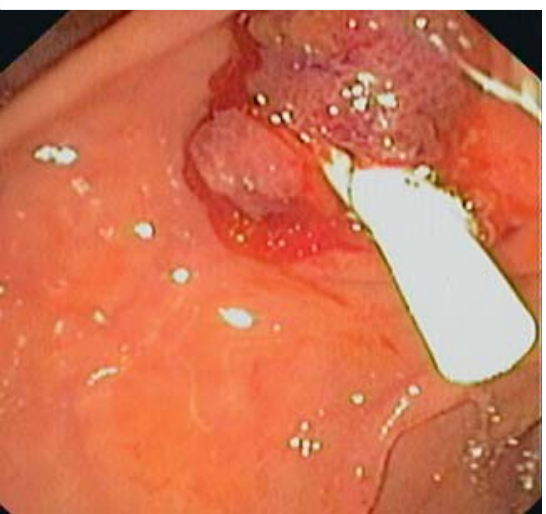

Fig. 5 A 10-Fr plastic stent, $7 \mathrm{~cm}$ long, inserted into the common bile duct.

\section{Prachayakul, P. Aswakul, U. Kachintorn}

Siriraj Endoscopy Center, Department of Internal Medicine, Siriraj Hospital, Mahidol University, Bangkok, Thailand

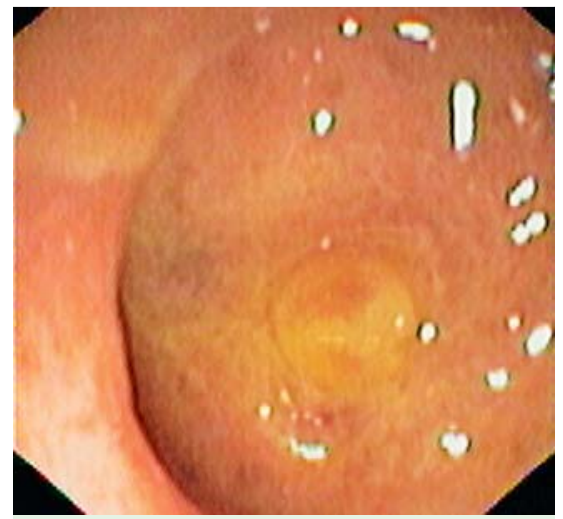

Fig. 6 Cholangioscopic view showing only a small ulcer at the distal common bile duct.

\section{References}

$1 \mathrm{Kim}$ B, Joo S, Joo K. Carcinoma in situ arising in a tubulovillous adenoma of the distal common bile duct: A case report. World J Gastroenterol 2008; 14: 4705 - 4708

$2 \mathrm{Kim}$ J, Moon J, Choi $\mathrm{H}$ et al. Endoscopic snare papillectomy by using a balloon catheter for an unexposed ampullary adenoma with in- traductal extension (with videos). GIE 2009; 69: $1404-1406$

3 Munshi A, Hassan M. Common bile duct adenoma: case report and brief review of the literature. Surg Laparosc Endosc Percutan Tech 2010; 20: 193-194

\section{Bibliography}

DOI http://dx.doi.org/

10.1055/s-0031-1291497

Endoscopy 2012; 44: E11-E12

(c) Georg Thieme Verlag KG

Stuttgart · New York

ISSN 0013-726X

\section{Corresponding author}

\section{Prachayakul, MD}

Division of Gastroenterology

Department of Internal Medicine

Faculty of Medicine

Siriraj Hospital

Mahidol University

Bangkok

Thailand

Fax: +662-4199610

kaiyjr@gmail.com 